\title{
PROCESSO EDUCATIVO NA SAÚDE: COMO TORNAR “VIVO" O ENSINO NOS AMBIENTES VIRTUAIS DE APRENDIZAGEM, EM UM MOMENTO DE PANDEMIA?
}

\author{
F. M. S. EINLOFT ${ }^{1}$, D. DORNFELD ${ }^{2}$, C. B. SOSTER ${ }^{3}$, M. DA R. FERREIRA ${ }^{4}$ \\ Grupo Hospitalar Conceição \\ ORCID ID: https://orcid.org/0000-0002-5905-6661 ${ }^{3}$ \\ cecilia.soster@gmail.com
}

Submetido 22/06/2020 - Aceito 23/11/2020

DOI: $10.15628 /$ holos. 2020.10540

\section{RESUMO}

A pandemia pela COVID-19 e a recomendação do isolamento social/espacial impuseram a suspensão das aulas presenciais, afetando as instituições de ensino no País. Porém, as escolas de formação em saúde viram-se pressionadas a manterem a formação para atender às demandas dos serviços por profissionais. Este trabalho visa relatar a experiência de adaptação do processo de formação, da modalidade presencial para a não presencial, de um Curso Técnico em Enfermagem. Esta escrita surgiu da iniciativa de convergir uma abordagem teórico-metodológica já utilizada no campo da saúde, "o trabalho vivo em ato" de Merhy, com os pressupostos sobre o processo de ensino-aprendizagem, de Paulo Freire. Foi urgente, às docentes do Curso, a busca pela formação e o conhecimento sobre os ambientes virtuais de aprendizagem. As reflexões que emergiram, a partir dessa experiência, concluíram que a contemporaneidade e o acesso facilitado às tecnologias da informação demandam um reposicionamento docente e discente em relação a elas. Qualquer que seja a metodologia utilizada em processos de ensino e aprendizagem, os melhores resultados foram encontrados naquelas que proporcionaram a construção do conhecimento de forma coletiva e dialógica. A convivência física, não sendo possível em um momento de isolamento espacial, foi substituída por ferramentas que possibilitaram o "convívio virtual" entre docentes e discentes.

PALAVRAS-CHAVE: Saúde e educação; Ensino Técnico; Processo de Ensino-Aprendizagem; Ambiente Virtual de Aprendizagem; Tecnologia Educacional.

\section{EDUCATIONAL PROCESS IN HEALTH: HOW TO MAKE TEACHING "LIVE" IN VIRTUAL LEARNING ENVIRONMENTS, AT A TIME OF PANDEMIC?}

\begin{abstract}
The COVID-19 pandemic and the recommendation of social / spatial isolation imposed the suspension of faceto-face classes, affecting educational institutions in the country. However, health training schools were under pressure to keep training to meet the demands of professional services. This work aims to report the experience of adapting the training process, from the face-to-face to the non-face-to-face modality, of a Technical Course in Nursing. This essay emerged from the initiative to converge theoretical and methodological approach already used in the health field, "live work in action" from Merhy, with assumptions about the teaching-learning process, from Paulo Freire. It was urgent for the teachers of the course
\end{abstract}

to seek training and knowledge about virtual learning environments. The reflections that emerged, from that experience, concluded that contemporary time and easier access to information technologies require a new adaptation of teachers and students in relation to them. Whatever the methodology used in teaching and learning processes, the best results were found in those that provided the construction of knowledge in a collective and dialogical way. Physical coexistence, not being possible at a time of spatial isolation, was replaced by tools that enabled "virtual coexistence" between teachers and students.

KEYWORDS: Education e Health; Technical education; Teaching-Learning Process; Virtual-Learning environment; Educational technology. 


\section{INTRODUÇÃO}

Em dezembro de 2019, na província de Hubei, na China, foi identificado um tipo de Coronavírus, até então desconhecido, capaz de desencadear um quadro respiratório, um tipo de pneumonia, em seres humanos (Organização Pan-americana de Saúde, 2020). Estudos sugerem uma baixa patogenicidade no SARS-CoV-2 (81\% dos infectados sintomáticos apresentam sintomas leves), causador da COVID-19. Comparada com outras epidemias provocadas por Coronavírus, como a Síndrome Respiratória do Oriente Médio (MERS-CoV) e a Síndrome Respiratória Aguda Grave (SARS-CoV), sua transmissibilidade apresentou-se mais potente, chegando ao dobro da capacidade de transmissão desses outros Coronavírus (Cowling et al., 2020).

Potencializado pela grande mobilidade da população, produto da globalização, rapidamente, esse vírus espalhou-se no mundo, sendo declarada Emergência de Saúde Pública de Importância Internacional, em 30 de janeiro de 2020. A COVID-19 foi caracterizada como Pandemia pela Organização Mundial de Saúde, no dia 11 de março de 2020 (Organização Pan-americana de Saúde, 2020).

Diversas recomendações vêm sendo desenvolvidas e testadas: individuais, aquelas que reduzem o risco de transmissão entre as pessoas, como a lavagem das mãos, o distanciamento e a etiqueta respiratória; medidas comunitárias para reduzir o contato na população, como a suspensão de eventos que favorecem a aglomeração de pessoas, o fechamento de locais que prestam serviços não essenciais e de estabelecimentos de educação, bem como redução da ocupação no transporte público; medidas para reduzir o risco de importação ou reintrodução do vírus, com limitação de passageiros em viagens nacionais e internacionais, triagem aprimorada e quarentena; dentre outras (World Health Organization, 2020).

Até o momento, a medida mais concreta e amplamente defendida pela Organização Mundial de Saúde para o controle da disseminação do SARS-Cov-2 é o isolamento social, ou "isolamento espacial", como descrito por Abel e McQueen (2020), no intuito de diminuir o impacto psicológico dessa indicação. Ela implica no distanciamento físico e restrições de movimento, por dois a três meses, podendo ser prorrogado, de acordo com o monitoramento da progressão da doença, com base nas experiências dos países afetados pela primeira vez por COVID-19 (World Health Organization, 2020).

Estudos identificaram reduções significativas na transmissão comunitária do SARS-CoV-2 a partir da adoção de medidas de isolamento espacial, e essas medidas têm efeito potencializado se iniciativas governamentais para impedir aglomerações de pessoas forem adotadas concomitantes a isso. A suspensão das aulas presenciais é uma dessas medidas que afetou diretamente as instituições de ensino, principalmente, as instituições de ensino em saúde, uma vez que, além da suspensão das aulas presenciais, viveu a pressão de formação dos profissionais para atender as demandas dos serviços de saúde, tendo em vista que $10 \%$ dos infectados pelo SARS-CoV-2 são profissionais de saúde (Organização Pan-americana de Saúde, 2020). 
O Curso Técnico em Enfermagem da Escola GHC foi criado em 2009, sob custeio do Ministério da Saúde. É oferecido gratuitamente e tem como concepção político-pedagógica formar profissionais, mediante uma educação transformadora, com enfoque no cuidado centrado nas necessidades do usuário, no trabalho em equipe, pautado por práticas cuidadoras e no compromisso com o fortalecimento do Sistema Único de Saúde (SUS), tendo como perspectiva a formação cidadã. A Escola GHC pertence à Gerência de Ensino e Pesquisa GHC, sendo esta uma das unidades que compõem a rede de serviços do Grupo Hospitalar Conceição (GHC). O GHC é referência no atendimento do SUS, constituído por quatro unidades hospitalares, uma Unidade de Pronto Atendimento (UPA), doze Unidades de Saúde (US) da Gerência de Saúde Comunitária, três Centros de Atenção Psicossocial (CAPS) e a Escola GHC. Vinculada ao Ministério da Saúde, essa estrutura forma a maior rede pública de hospitais do Sul do País, com atendimento 100\% SUS (Brasil. Ministério da Saúde. Grupo Hospitalar Conceição, 2020).

Nesse pressuposto, a matriz curricular está embasada no ciclo de vida do indivíduo e nas necessidades de saúde da população, sendo transversalizada pelos temas de integralidade da atenção e do trabalho em rede. É constituída por quatro unidades temáticas - Políticas Públicas de Cidadania e SUS; Atenção Integral em Saúde; Fundamentos, Tecnologias e Práticas em Saúde; e Estágio - que norteiam a organização dos conteúdos a serem trabalhados ao longo dos quatro semestres do Curso. O corpo docente é formado por enfermeiras e outros profissionais da saúde e de outros campos de conhecimento do GHC, que têm sua carga horária compartilhada entre assistência e docência, sendo esta uma característica diferencial do curso. A experiência adquirida a partir do cotidiano da prática assistencial dos docentes, aliada à sua formação acadêmica (mestrado e doutorado), tem sido enriquecedora para os espaços teóricos e as práticas do Curso.

Este artigo visa compartilhar a experiência de adaptação do processo de formação, da modalidade presencial para a não presencial, das aulas no Curso Técnico em Enfermagem da Escola GHC, motivada pela pandemia por COVID-19, que levou a refletir sobre as seguintes questões. Como manter "viva" uma aula a distância? Como não perder o foco daquilo que acontece em sala de aula quando a construção do conhecimento acontece em ambientes de aprendizagem virtual, com estudantes na saúde? Este trabalho está estruturado em três tópicos. Inicialmente, serão introduzidos os aspectos relacionados ao ambiente virtual de aprendizagem e as ferramentas experimentadas pelas docentes. Em seguida, será mencionado o processo de virtualização do Curso, a partir das teorias utilizadas no campo da saúde (Merhy, 2013) e da educação (Freire, 1987) e, por fim, serão apresentados os resultados e a discussão sobre as estratégias que tornaram "vivo" o ensino a distância. 


\section{FERRAMENTAS VIRTUAIS EXPERIMENTADAS}

Tendo em vista o momento da pandemia, em caráter excepcional, foi autorizado, pelo Ministério da Educação ${ }^{1}$, o ensino presencial mediado por tecnologias de informação e comunicação. Este estudo descritivo relata a experiência de três docentes enfermeiras, do Curso Técnico em Enfermagem, na manutenção da formação de duas turmas, totalizando cinquenta e cinco discentes. No processo de adaptação do Curso, da modalidade presencial para o formato virtual, fez-se necessária a busca de referencial teórico sobre o ensino a distância: os pressupostos e as ferramentas metodológicas utilizadas. A potencialidade dos artefatos tecnológicos na mediação do trabalho docente e as possibilidades de associação de ferramentas digitais às metodologias de ensino e as práticas de pesquisa foram questionadas por Porto, Oliveira e Chagas (2017), assim como dois aspectos também preocuparam as docentes: o primeiro era que o Curso mantivesse sua identidade e sua qualidade; o segundo, que as aulas fossem acessíveis a todos os discentes.

Para esta reflexão, foi utilizado um referencial do campo da saúde, que aborda as diferentes tecnologias, a partir da valise utilizada pelo médico. Fez-se uma leitura do trabalho docente, a partir dessa perspectiva teórica. Merhy (2013) considera as valises utilizadas pelo médico, no seu encontro com os usuários, como caixas de ferramentas tecnológicas. $O$ autor as considera de três tipos: as "tecnologias duras" (compostas pelos equipamentos); "tecnologias leve-duras" (que estão na cabeça do médico, na qual cabem saberes estruturados) e "tecnologias leves" (presentes no espaço relacional, entre dois sujeitos, que têm sua materialidade em ato). Tomaram-se esses conceitos para refletir sobre o processo de ensino-aprendizagem. Na educação, o docente pode contar com tecnologias duras, como por exemplo: quadro branco, pincéis, recursos tecnológicos, entre outras; as tecnologias leve-duras são constituídas pelo saber dos docentes referentes aos temas ensinados, e as tecnologias leves, materializadas no encontro entre o docente e o discente. Partindo de tal pressuposto teórico, diversas tecnologias duras foram experimentadas pelas docentes, na busca de encontrar aquelas que mantivessem a aproximação e o vínculo entre docentes e discentes, bem como a identidade do Curso Técnico em Enfermagem da Escola GHC.

O primeiro passo foi a análise cuidadosa da matriz de ensino para organização do novo cronograma. A primeira reunião, das muitas que ocorreram nesse tempo, teve como pauta principal identificar quais conteúdos poderiam ser ensinados a distância, desde que fosse garantido o processo de construção do conhecimento com os discentes e o comprometimento com seu aprendizado. Foram elencadas as temáticas que poderiam ser trabalhadas nesse formato, e alguns conteúdos foram adiados para o próximo semestre, por se tratarem de temáticas que exigiam a demonstração prática e o treino pelo discente.

Logo na sequência, foram urgentes a busca pela formação e o conhecimento sobre os ambientes virtuais de aprendizagem, no caso deste relato, a plataforma disponibilizada pela Escola

\footnotetext{
${ }^{1}$ Através da Portaria no 376, de 3 de abril de 2020, o Ministério da Educação autoriza, em caráter excepcional, que as instituições de educação profissional técnica de nível médio substituam as aulas presenciais por atividades não presenciais, desde que respeitadas as cargas horárias e matriz curricular (Brasil. Ministério da Educação, 2020).
}

HOLOS, Ano 36, v.5, e10540, 2020 
GHC, o Moodle. Moodle é o acrônimo para Modular Object Oriented Distance Learning (Claro, 2018). Trata-se de um modelo em software livre, utilizado para a criação de cursos on-line, sendo uma alternativa importante no enfrentamento do problema imposto pela pandemia. Ele concentra, em um único espaço, todas as informações relativas ao curso. Dessa forma, as docentes disponibilizavam os materiais referentes a cada temática que seria utilizada para a construção do conhecimento: arquivos de texto, links, vídeos, áudios, imagens, gráficos, bem como atividades avaliativas.

Uma ferramenta muito utilizada foi a do Rótulo, pela qual as docentes deixavam mensagens relatando a falta que o encontro com os discentes fazia, bem como eram passadas orientações para o desenvolvimento do aprendizado. Trata-se de uma ferramenta que proporciona uma interação entre docentes e discentes. Outras ferramentas experimentadas via Moodle foram os recursos (Livro, Arquivo, URL) e as atividades (Fórum, Wiki, Questionário e Tarefa).

Por meio do recurso Livro, é possível exibir grande quantidade de informações organizadas em seções, como em capítulos e subcapítulos. Assim, foram trabalhados conteúdos a partir da disponibilização de arquivos de mídia, imagens, apresentações em PowerPoint e documentos em PDF, atrelados a atividades que permitiram acompanhar a apropriação dos conteúdos pelos discentes. Assim como o Livro, o Arquivo possibilita incluir arquivos nos diversos formatos e foi um recurso frequentemente utilizado pelas docentes para a mesma finalidade. O URL é um recurso que permite, ao docente, fornecer um link que direciona o discente a uma página web. Esse recurso foi muito utilizado para indicar o acompanhamento de documentários, filmes, reportagens e os vídeos produzidos pelas docentes e postados no canal do Curso no YouTube.

O Fórum é uma atividade do Moodle que permite, aos participantes, realizar discussões que acontecem durante um período de tempo determinado. Por meio do Fórum, foram promovidas conversas assíncronas, através de texto, com os discentes, onde refletiram sobre temas relacionados ao cuidado de enfermagem, demandando, inclusive, que fizessem busca e postagem de documentos científicos que embasassem suas argumentações. Os discentes também apresentaram trabalhos produzidos em pequenos grupos. Essa ferramenta de interação permitiu que os colegas comentassem e complementassem as informações uns dos outros, configurando-se em um espaço de construção de conhecimento bastante ativo. Outra utilização do Fórum foi como um espaço para dúvidas e perguntas sobre determinado conteúdo e para revisão comentada das questões de avaliação.

O Wiki permite, aos participantes, adicionar e editar uma coleção de páginas da internet. Um Wiki pode ser colaborativo, com todos podendo editá-lo, ou individual, onde cada um tem seu próprio Wiki e somente ele pode editar. Um histórico de versões anteriores de cada página do Wiki é mantido, listando as edições feitas por cada participante. Por meio dessa ferramenta, foram propostas construções coletivas de resenha crítica sobre um filme indicado, da admissão de enfermagem em uma unidade de internação e de estudos de casos. O Questionário permite criar e configurar uma atividade com questões de vários tipos (múltipla escolha, verdadeiro ou falso, correspondência, resposta curta, entre outras). Essa ferramenta do Moodle foi utilizada para aplicação de pequenos testes para revisão de conteúdos no final de um tópico. 
$\mathrm{Na}$ atividade Tarefa, é possível comunicar tarefas, recolher o trabalho e fornecer notas e comentários. Os discentes podem apresentar qualquer conteúdo digital de autoria própria ou referenciado. Ao analisar os trabalhos, os docentes podem postar devolutivas em formato de comentários, arquivos ou áudios. Dentre as atividades disponíveis no Moodle, essa foi mais uma ferramenta utilizada pelas docentes, ao proporem escritas referentes à análise de textos, vídeos, imagens e demais reflexões sobre o cuidado desempenhado pelo Técnico de Enfermagem, frente aos diversos conteúdos abordados.

O ambiente do Moodle também possibilitou, às docentes, monitorar o desempenho dos discentes. A revisão de relatórios de acesso e conclusão das atividades permitiu identificar se o discente acessou todos os materiais postados, quantas visualizações aconteceram, se realizou as atividades, se a conclusão ocorreu no tempo determinado e as notas ou pareceres das avaliações das respectivas atividades. Todas essas informações foram fundamentais para o fórum avaliativo do Curso, o qual consiste em um espaço onde o discente é avaliado de forma integral, para além dos aspectos de conhecimento técnico, sendo considerados habilidades relacionais, postura ética e desenvolvimento ao longo do semestre.

\section{O PROCESSO DE VIRTUALIZAÇÃO DO CURSO}

À medida que as docentes experimentavam os diferentes recursos da plataforma Moodle, foram escolhidos aqueles que possibilitavam a maior integração entre discentes e docentes e favoreciam a construção horizontal do conhecimento. O objetivo sempre foi construir o saber de forma dialógica, evitando a transmissão de conhecimento, no formato da Educação Bancária (Freire, 1987). É papel do educador trabalhar, junto ao educando, a rigorosidade metódica, que vai além do tratamento do objeto ou do conteúdo. Trata-se de acreditar que aprender criticamente é possível (Freire, 1996).

Essa preocupação demandou, das docentes, uma exaustiva elaboração de material a ser apresentado nos mais diversos formatos. A produção de vídeos com as docentes do Curso comentando os conteúdos ou, muitas vezes, demonstrando alguns procedimentos técnicos e cuidados de enfermagem, logo, surgiu como uma necessidade. Para dar mais identidade aos vídeos produzidos exclusivamente para os discentes do Curso, uma vinheta de abertura foi criada. Ela introduziu cada atividade proposta em formato MP4 e contou com a identidade visual da Escola GHC e do Curso Técnico em Enfermagem.

Observou-se, também, a demanda por parte dos discentes de esclarecimentos em relação às atividades propostas. Algumas delas não foram facilmente compreendidas no momento da apresentação da tarefa. Para minimizar as dificuldades quanto ao uso das tecnologias por parte dos discentes, foram utilizados, como estratégia, vídeos tutoriais produzidos e filmados pelas docentes e enviados pelo WhatsApp ${ }^{2}$.

${ }^{2} O$ WhatsApp foi introduzido, no Brasil, em 2009. Para os brasileiros, os serviços móveis de mensagens são as atividades mais utilizadas no Smartphone. Desde 2017, 56\% de toda a população brasileira faz uso do WhatsApp (Bucher, 2019). 
É incontestável a popularidade do WhatsApp, especialmente entre os mais jovens (Porto et al., 2017). Observou-se que todos os discentes tinham acesso a ele, por isso, foi um recurso muito utilizado pelas docentes para esclarecimentos e feedbacks sobre atividades. Assim, o WhatsApp serviu como um canal de contato direto entre docentes e discentes: áudios, vídeos e mensagens de texto foram encaminhados para os discentes, bem como dúvidas e perguntas sobre as atividades eram acolhidas por essa ferramenta.

Dois programas para edição de vídeos foram utilizados (CHENGDU Yiwo ${ }^{\circledR}$ Tech Development Co. Ltd., 2020; OBS Project, 2020). Ambos são disponibilizados gratuitamente e escolhidos por se apresentarem como softwares mais amigáveis para as docentes, que ainda não tinham experiência nessa prática. Os programas oferecem múltiplos recursos de efeitos e filtros, que qualificaram os vídeos para o Curso Técnico em Enfermagem, permitindo a inclusão da vinheta, a correção de erros e falhas durante as gravações e o uso da criatividade por parte das docentes. Além desses, foram utilizados também aplicativos de gravação para Smartphone (Apple Inc., 2019), que permitiram a gravação, a edição e o compartilhamento de áudios de forma rápida e prática.

Foi criado um canal do Curso no YouTube, plataforma utilizada para postagem de vídeos produzidos pelas docentes do Curso. O YouTube foi criado em fevereiro de 2005 em virtude do inconveniente que era compartilhar arquivos de vídeo, já que estes eram muito grandes, o que dificultava seu envio por e-mail. O site permite que os usuários coloquem seus próprios vídeos na rede, sendo visualizados por qualquer pessoa no mundo inteiro. Atualmente, é uma das plataformas mais aceitas pelos educadores, em nível mundial, para compartilhar vídeos educacionais (Villalobos \& Garza, 2017).

Utilizando-se dispositivos de reuniões/conferências on-line disponíveis gratuitamente (WebEx Communications, 2020), as aulas síncronas constituíram-se como uma alternativa que mais se aproximava do encontro que acontecera presencialmente. Estas eram avisadas com antecedência, seguindo o calendário proposto, para que os discentes conseguissem organizar-se para o acesso. Contou-se com a participação de uma média de 95\% em uma turma e uma média de $60 \%$ na outra. Essa última turma tinha mais alunos com limitações na acessibilidade à internet. A sala de aula virtual possibilitou uma interação muito interessante, que não era viável com o uso de outras ferramentas. Foi um encontro de vozes, olhares e pensamentos muito potente para uma prática mais dialógica do processo ensino-aprendizagem.

As chamadas telefônicas também foram um recurso utilizado pelas docentes para contato com os discentes nas seguintes situações: orientações sobre o novo formato do Curso, esclarecimentos de dúvidas, acolhimento de dificuldades e escuta de angústias.

\section{DISCUSSÃO}

As práticas culturais, na atualidade, estão permeadas por artefatos digitais tanto no que se refere às relações comunicacionais, como, também, aos novos modos de aprendizado e de acesso à informação. Isso desafia docentes e escolas de formação. Surgem tensões na prática docente e nos processos educativos, que sentem certo estranhamento aos hábitos na cultura contemporânea. 
Estudiosos da Cibercultura atribuem, aos jovens, a denominação de nativos digitais e aqueles que nasceram antes dos anos de 1990 como imigrantes digitais (Porto et al., 2017).

É desse lugar de "imigrantes digitais" que as docentes do Curso partiram para o desafio de aprender e ensinar: de aprender a operar as novas ferramentas e de ensinar a partir dessas novas descobertas. Na modalidade não presencial, o docente pode escolher entre diferentes tipos de tecnologias. Mas quais delas podem facilitar um aprendizado mais integrado e dialógico, que proporcione, ao educando, uma construção do conhecimento de forma autônoma e, ao mesmo tempo, compartilhada com docentes e outros discentes? Qual das tecnologias disponíveis torna "viva" uma sala de aula virtual?

Merhy (2013) analisa os componentes do processo de trabalho de um artesão-marceneiro, no qual estão sempre presentes: o trabalho em si do marceneiro, as matérias-primas e as ferramentas ou instrumentos de trabalho. A simples existência desses três componentes não necessariamente produzirá um móvel. É necessária a articulação entre eles, orientada por um projeto que os une. É o ato vivo, do artesão, o que o autor chama de saber tecnológico, certo modo de saber fazer que os transforma em um produto final. No trabalho docente, não é diferente. Há um trabalho morto no processo de trabalho do marceneiro, assim como no trabalho do docente. Assim como o martelo do marceneiro, o docente conta com um quadro, com o pincel e, neste momento, com aplicativos, softwares, hardwares e outros recursos tecnológicos. Ressalta-se uma diferença interessante entre o marceneiro e o professor: a matéria-prima do trabalho do educador não é um objeto inerte, mas, sim, um sujeito. É o trabalho em ato, vivo, que acontece a partir do encontro entre sujeitos, que contribui para a transformação do discente. $O$ autor chama de trabalho vivo, o trabalho criador, e de trabalho morto, os meios utilizados para se chegar a um produto final. Àquilo que está dado, as ferramentas tecnológicas, soma-se um saber ser professor, a sua autonomia e o seu autogoverno, que, a partir da ação do seu trabalho vivo em ato, pensa um caminho que será percorrido pelo discente para construção do conhecimento. No trabalho em saúde, há um espaço intercessor entre o usuário e o trabalhador. $O$ autor fala de um encontro e de uma negociação entre usuários dos serviços de saúde e os trabalhadores, em ato, dos encontros de necessidades, que também se percebe na relação docente e discente. $O$ trabalho vivo é processual e sustentado nas relações, sendo este potencialmente transformador.

A construção de um conhecimento mais consistente por parte dos discentes tem maior chance de ocorrer quando existe uma ação docente mediadora e comunicativa. Ela deve estimular a utilização reflexiva e autônoma das ferramentas de ensino-aprendizagem, bem como a adoção de uma postura dialógica entre os sujeitos. As propostas educacionais que orientam esse processo devem ter como base, para além da capacitação dos sujeitos, a completa realização do potencial dos discentes (Rocha et al., 2018). Dessa forma, buscou-se produzir processos que colocassem o discente como centro, refletindo sobre a possibilidade de um aprendizado de qualidade. Em tal contexto, percebeu-se que, no conjunto de saberes do docente, para além do domínio do conteúdo a ensinar, são exigidos outros saberes a fim de tornar o ambiente de aprendizado virtual um lugar onde o discente aprenda pelo incentivo à participação, à autonomia, ao diálogo e à construção (Carmo \& Franco, 2019). Assim, algumas das ferramentas utilizadas, ao reproduzirem um tipo de 
aprendizado não condizente com os pressupostos teóricos que sustentam o fazer docente neste Curso, foram substituídas por outras que oportunizaram mais reflexão e integração.

A produção dos vídeos (aulas comentadas, demonstração de procedimentos) e a realização de aulas síncronas tiveram um papel muito importante no sentido de amenizar o sentimento de distanciamento imposto, percebido tanto pelos discentes quanto pelas docentes. Após a postagem das aulas nesse formato, os discentes, frequentemente, enviavam mensagens valorizando a importância de visualizar sua docente, explicando e discutindo o conteúdo abordado. Da mesma forma, durante a gravação dos vídeos e áudios, era inevitável algum comentário da docente, em que salientava o sentimento de saudade de poder encontrar seus discentes presencialmente. Além de estimularem - a partir do debate - a construção do conhecimento embasado nas vivências e experiências compartilhadas pelos discentes, com esses formatos, percebeu-se o quanto a imagem e a voz confortam em momentos como este de pandemia. A ausência do contato face a face e a perda dos elementos da linguagem corporal, presentes na interação proporcionada pelo encontro presencial, podem ser fatores desestabilizantes para docentes e discentes e consistem em um desafio para a mediação pedagógica no ambiente virtual de aprendizagem (Carmo \& Franco, 2019). Ensinar, criticamente, exige criação, inquietação, curiosidade, humildade e persistência dos educadores e educandos. Exige, do educador, a consciência de que, para além dos conteúdos, precisa-se ensinar a pensar certo (Freire, 1996). Houve momentos em que, além da problematização e do conhecimento construídos dentro dos objetivos do eixo temático, as docentes identificaram dificuldades e situações de sofrimento entre os discentes, quando puderam intervir, ajudando-os.

Se estivessem vivos, Freire, Vygotsky, Freinet, Dewey e Teixeira usariam o Smartphone, o tablet e o laptop como aliados em sala de aula. Para além da possibilidade da transmissão de filmes, para leitura de textos e para ouvir áudio, aproveitariam as potências desses dispositivos como ambientes de imersão, de manipulação e de interlocução. Perceberiam que o tripé da comunicação, emissor/mensagem/receptor, atualmente, passa por uma mudança favorável a suas concepções de educação: "mensagem muda de natureza, o emissor muda de papel e o receptor muda de status". O emissor oferece um leque de elementos e possibilidades à manipulação do receptor, que é convidado à autoria colaborativa. Ele passa a poder intervir na mensagem, que por sua vez, passa a ser modificável. Se estivessem vivos, essas referências do campo da Educação, possivelmente, utilizariam o WhatsApp, que facilita o processo de ensino-aprendizagem, na medida em que reúne "interlocutores em bidirecionalidade, multidirecionalidade, comunicação síncrona e assíncrona, com troca de texto, áudio, imagem e vídeo, documentos em PDF e ligações gratuitas por meio de conexão com a internet" (Silva, 2017, p. 16-17).

Os dispositivos móveis são potenciais ferramentas para o desenvolvimento de estratégias e técnicas de aprendizagem. Têm amplo uso, quase todas as pessoas possuem acesso a essa tecnologia, sendo o mobile learning um conceito cada vez mais assumido pelo campo da Educação (Moreira \& Trindade, 2017).

Muitas são as ferramentas disponíveis para uso no campo da educação, o que demandou pesquisa no que se refere às tecnologias e como utilizá-las. Um educador ensina porque busca, porque indaga, porque se indaga. O desafio do uso das tecnologias para ensinar colocou, em 
movimento de pesquisa, as docentes deste Curso técnico. Experimentou-se muitas das exigências do ensinar, quais sejam: a pesquisa dos novos recursos e como utilizá-los; o risco que essa novidade trouxe na construção docente, como falhas e erros na programação de algumas atividades; a aceitação do novo, tanto pelo corpo docente como pelos discentes; a reflexão crítica diária sobre a prática de ensinar, com muita discussão e elaboração entre as docentes; o respeito à autonomia dos educandos; a humildade no reconhecimento de que alguns conhecimentos não eram de seu domínio; curiosidade e ousadia no desafio diário de se arriscar no uso de uma nova ferramenta virtual; a generosidade entre as docentes de se ajudar mutuamente no novo desafio, bem como entre discentes de compartilhar as dificuldades e os caminhos encontrados; um comprometimento de educadoras e educandos com o acesso à plataforma, realização das atividades e feedbacks; a exigência da escuta e do diálogo, uma vez que, fora os sentimentos provocados pela própria pandemia, as angústias e as ansiedades impostas pelo uso de tecnologias desconhecidas trouxeram a necessidade de encontros virtuais com os alunos para além da abordagem de conteúdos. Experimentou-se o quanto o educador precisa querer bem aos seus educandos e o quanto ensinar exige alegria e esperança. Os tempos de pandemia demonstraram o quanto uma relação horizontal e próxima entre docentes e discentes facilita o enfrentamento do isolamento, da distância e das angústias sentidas e vividas (Freire, 1996).

O ambiente de aprendizagem virtual pode facilitar a construção compartilhada do conhecimento, potencializando o ensino, já que a aprendizagem centraliza-se no discente ao desenvolver habilidade de comunicação e obter conhecimento de maneira autônoma. Mas traz, também, uma novidade para os discentes, que é a procura e a busca pelo conhecimento. Percebeuse uma dificuldade de poucos discentes nesse novo processo, que demanda mais autonomia e maturidade. Especialmente, uma discente demonstrou mais dificuldade na modalidade a distância, o que não havia se apresentado dessa forma na modalidade presencial.

Acredita-se na potência de educandos pensantes, críticos e questionadores. Para isso, foram escolhidas as tecnologias que mais facilitaram a construção compartilhada do conhecimento, aquelas que davam vida ao processo de ensino aprendizagem. Um processo não apenas para ensinar as pessoas a se adaptarem a uma realidade, mas para sentirem-se livres para nela intervirem, recriá-la e transformá-la (Habowski et al., 2020).

\section{CONSIDERAÇÕES FINAIS}

A contemporaneidade e o acesso facilitado às tecnologias da informação demandam um reposicionamento docente e discente em relação a elas. Este relato apresentou o uso do ambiente virtual de aprendizagem, em uma situação emergencial, imposta pelo distanciamento físico exigido pela pandemia. Qualquer que seja a metodologia utilizada em processos de ensino e aprendizagem, os melhores resultados foram encontrados naquelas que proporcionaram a construção do conhecimento de forma coletiva e dialógica. A convivência física, não sendo possível em um momento de isolamento espacial, foi substituída por ferramentas que possibilitaram o "convívio virtual" entre docentes e discentes. 
Concluiu-se, com esta experiência, que uma aula "viva" pode acontecer a partir do uso de inúmeras tecnologias, mas aquelas que ofertam dispositivos de encontros, especialmente os síncronos, mostraram-se mais potentes, uma vez que a construção do conhecimento acontece na coletividade da sala virtual, de forma interativa e dialógica.

Este estudo apresenta limitações, tendo em vista tratar-se de um registro do uso de ambientes virtuais de aprendizagem em um momento de pandemia, o que, por si, já fragiliza as pessoas e pode interferir no processo de ensino-aprendizagem. Faz-se necessária a exploração desse tema também em outro momento, contando com outros delineamentos, para análise mais pormenorizada do uso de tecnologias virtuais na formação de Técnicos de Enfermagem.

Tendo em vista a necessidade do treino para realização de procedimentos pelo discente, desenvolvido em laboratório e campos de prática, a oferta de um curso de formação dessa categoria profissional não pode ser pensada, na sua integralidade, no formato virtual.

Embora a plataforma Moodle, o WhatsApp e outras ferramentas tecnológicas tenham sido utilizados em resposta a uma necessidade do Curso, devido à pandemia do COVID-19, percebeu-se seu potencial como recurso complementar nas aulas em modalidade presencial, uma vez que o ensino virtual pode abranger mais estudantes, otimizar o tempo e ter menor custo, promovendo a democratização da educação na saúde.

\section{REFERÊNCIAS}

Abel, T., \& McQueen, D. (2020). The COVID-19 pandemic calls for spatialConceição, G. H. (n.d.). Grupo Hospitalar Conceição. $\quad$ Retrieved from http://pesquisa.bvsalud.org/bvsms/resource/pt/mis-24305 distancing and social closeness: not for social distancing! International Journal of Public Health, 65(3), 231. https://doi.org/10.1007/s00038-020-01366-7

Apple Inc. (2019). Gravador. https://support.apple.com/pt-br/HT206775

Brasil. Ministério da Saúde. Grupo Hospitalar Conceição. (2020). Grupo Hospitalar Conceição (p. 11). ghc.com.br

Brasil, \& Ministério da Educação. (2020). PORTARIA N³ 376, DE 3 DE ABRIL DE 2020. Diario Oficial $D a$ União, 66 , http://pesquisa.in.gov.br/imprensa/jsp/visualiza/index.jsp?data=06/04/2020\&jornal=515\&pa gina $=66$

Bucher, B. (2019). 98\% dos usuários brasileiros de smartphones usam o WhatsApp diariamente. Messengerpeople, 1-7. https://www.messengerpeople.com/pt-br/whatsapp-no-brasil/

Carmo, R. de O. S., \& Franco, A. P. (2019). DA DOCÊNCIA PRESENCIAL À DOCÊNCIA ONLINE: APRENDIZAGENS DE PROFESSORES UNIVERSITÁRIOS NA EDUCAÇÃO A DISTÂNCIA. Educação Em Revista, 35(210399). https://doi.org/10.1590/0102-4698210399 
CHENGDU Yiwo ${ }^{\circledR}$ Tech Development Co. Ltd. (2020). EaseUS Video Editor Poderoso software editor de vídeo para expressar sua inspiração (14.0). https://br.easeus.com/multimedia/videoeditor.html

Claro, M. (2018). Plataforma Moodle: entenda o que é e como funciona. In 10 May 2018.

Cowling, B. J., Ali, S. T., Ng, T. W. Y., Tsang, T. K., Li, J. C. M., Fong, M. W., Liao, Q., Kwan, M. Y., Lee, S. L., Chiu, S. S., Wu, J. T., Wu, P., \& Leung, G. M. (2020). Impact assessment of nonpharmaceutical interventions against coronavirus disease 2019 and influenza in Hong Kong: an observational study. The Lancet Public Health, 5(5), e279-e288. https://doi.org/10.1016/S2468-2667(20)30090-6

Freire, P. (1987). Pedagogia do oprimido (17th ed.). Paz e Terra.

Freire, P. (1996). Pedagogia da autonomia: saberes necessários à prática educativa. Paz e Terra.

Habowski, A. C., Conte, E., \& Jacobi, D. F. (2020). Interlocuções e discursos de legitimação em EaD. Ensaio: Avaliação e Políticas Públicas Em Educação, 28(106), 178-197. https://doi.org/10.1590/s0104-40362019002701365

Merhy, E. E. (2013). Em busca do tempo perdido: a micropolítica do trabalho vivo em ato, em saúde. Org Túlio Batista Franco, Emerson Elias Merhy. 1 ed. São Paulo: Hicitec, 2013. p. 19 -67. In T. B. Franco \& E. E. Merhy (Eds.), Trabalho, produção do cuidado e subjetividade em saúde: textos reunidos (1st ed., pp. 19-67). Hicitec.

Moreira, J. A., \& Trindade, S. D. (2017). O WHATSAPP COMO DISPOSITIVO PEDAGÓGICO PARA A CRIAÇÃO DE ECOSSISTEMAS EDUCOMUNICATIVOS. In C. Porto, K. E. Oliveira, \& A. Chagas (Eds.), Whatsapp e educação: entre mensagens, imagens e sons (pp. 49-68). EDUFBA; EDITUS. https://doi.org/10.7476/9788523220204

OBS Project. (2020). Open Broadcaster Software (25.0.4). https://obsproject.com/pt-br

Organização Pan-Aamericana de Saúde. (2020). Folha informativa - COVID-19 (Doença causada pelo novo coronavírus). Organização Pan-americana Da Saúde. Organização Mundial Da Saúde; Organização Mundial de Saúde.

Porto, C., Oliveira, K. E., \& Chagas, A. [orgs. . (2017). EDUCAÇÃO MEDIADA PELO WHATSAPP: ENSINAR E APRENDER POR MENSAGENS INSTANTÂNEAS. In C. Porto, K. E. Oliveira, \& A. Chagas (Eds.), WHATSAPP E EDUCAÇÃO: Entre mensagens, imagens e sons (pp. 9-14). EDUFBA; EDITUS. https://doi.org/10.7476/9788523220204

Rocha, M. C., Branco, M. L., Simões, F., \& Falbo, G. (2018). CONSTRUÇÃO DE CONHECIMENTO EM AMBIENTE DIGITAL: A IMPORTÂNCIA DA PERSPECTIVA DIALÓGICA. Holos, 5(34), 151-161. https://doi.org/10.15628/holos.2018.4559

Silva, M. (2017). Paulo Freire, Vygotsky, Freinet, Dewey e Anísio Teixeira usariam o WhatsApp! In C. Porto, K. E. Oliveira, \& A. Chagas (Eds.), Whatsapp e educação entre mensagens, imagens e sons (pp. 15-27). EDUFBA; EDITUS. https://doi.org/10.7476/9788523220204 
Villalobos, C. M. R., \& Garza, J. F. (2017). Uso del recurso de contenido en el aprendizaje en línea: YouTube. Apertura, 9(1), 22-31. https://doi.org/10.18381/Ap.v9n1.1018

WebEx Communications. (2020). WebEx Meeting Center (40.4.10.8). https://www.webex.com/pt/index.html

World Health Organization. (2020). COVID-19 Strategy Up Date (Issue April). Word Health Organization. https://www.who.int/docs/default-source/coronaviruse/covid-strategy-update14april2020.pdf?sfvrsn=29da3ba0_19\&download=true

\section{COMO CITAR ESTE ARTIGO:}

Einloft, F. M. S., Dornfeld, D., Soster, C. B., Ferreira, M. da R. (2020). Processo educativo na saúde: como tornar "vivo" o ensino nos ambientes virtuais de aprendizagem, em um momento de pandemia?. Holos. 36(5), 1-14.

\section{SOBRE OS AUTORES}

\section{F. M. S. EINLOFT}

Possui graduação em Enfermagem pela Pontifícia Universidade Católica de Minas Gerais (2001). Atualmente é enfermeira da Gerência de Ensino e Pesquisa do Grupo Hospitalar Conceição. Tem experiência na área de Enfermagem, com ênfase em Enfermagem de Saúde Pública e Saúde da Família. Exerce atividades docente, na área de ensino em saúde. É facilitadora do Estágio (teórico-prático) de Gerenciamento da Residência Multiprofissional em saúde e Residência Médica. E-mail: efernanda@ghc.com.br ORCID ID: https://orcid.org/0000-0001-8402-5042

\section{DORNFELD}

Possui graduação em Enfermagem pela UFRGS (1999), especialização em Enfermagem Neonatal pela Escola de Saúde Pública do Rio Grande do Sul (2002), especialização em Informação Científica e Tecnológica em Saúde pela Fundação Oswaldo Cruz (2005) e Mestrado em Enfermagem pela Escola de Enfermagem da UFRGS (2011). Atualmente é docente na Escola GHC / Centro de Educação Tecnológica e Pesquisa em Saúde; coordenadora do Grupo de Incentivo ao Aleitamento Materno HNSC/HCC/SSC e supervisora do Programa Atenção Materno-Infantil e Obstetrícia da Residência Multiprofissional em Saúde do GHC. E-mail: dinara@ghc.com.br

ORCID ID: https://orcid.org/0000-0002-7566-4966

\section{B. SOSTER}

Graduada em Enfermagem pela Universidade Luterana do Brasil (2013). Especialista em Enfermagem de Emergência (2015). Mestranda do PPG Avaliação e Produção de Tecnologias para o SUS do Grupo Hospitalar Conceição (GHC). Atua como enfermeira docente na Escola GHC. Atua como voluntária no Departamento de Socorro e Desastres e Departamento de Migrantes da Cruz Vermelha Brasileira RS, nas áreas de resgate, instrução de cursos e formações e ações humanitárias de saúde. E-mail: cecilia.soster@gmail.com ORCID ID: https://orcid.org/0000-0002-5905-6661

\section{DA R. FERREIRA}

Possui Bacharelado e Licenciatura em Enfermagem pela Universidade Luterana Do Brasil (2007). Conclusão da especialização em Neonatologia pelo Centro Universitário São Camilo em 2012. Mestrado em Avaliação e Produção de Tecnologias em Saúde, no Centro de Educação Tecnológica e Pesquisa em Saúde- Grupo Hospitalar Conceição. Conclusão em Março de 2019. Especialização em Saúde Quântica pelo IBPEX, concluída 
em 2017. Atuou como docente das Escolas de Técnico de Enfermagem no Instituto Pró Universitário Canoense e Universitário de Alvorada de 2008 a 2014. De 2010 a 2015 atuou como enfermeira na linha de cuidados Mãe-bebê no Hospital Nossa Senhora da Conceição, atualmente desempenha a função de Responsável Técnica e docente do Curso Técnico em Enfermagem da escola Técnica do Grupo Hospitalar Conceição. Proprietária da empresa Sling Aconchego consultoria em Aleitamento Materno e cuidado infantil, ministra cursos de prevenção de acidentes e primeiros socorros na infância. E-mail: $\underline{\text { michelef@ghc.com.br }}$ ORCID ID: https://orcid.org/0000-0002-6325-840X

Editor(a) Responsável: Leandro Costa

Pareceristas Ad Hoc: LENINA SILVA E ADRIANA APARECIDA DE SOUZA

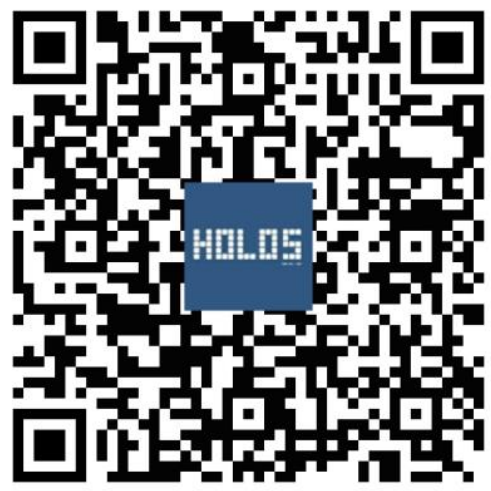

